\title{
MATH TOUCH: TECNOLOGIA ASSISTIVA PARA O DESENVOLVIMENTO DE CONCEITOS MATEMÁTICOS BÁSICOS
}

\section{MATH TOUCH: ASSISTIVE TECHNOLOGY FOR THE DEVELOPMENT OF BASIC MATHEMATICAL CONCEPTS}

\author{
Juliano Daniel Moeller ${ }^{1}$ \\ Maria Adelina Raupp Sganzerla ${ }^{2}$ \\ Marlise Geller ${ }^{3}$
}

\begin{abstract}
Resumo: Este artigo é um recorte da monografia de conclusão de curso em Ciências da Computação, descrevendo a implementação de uma Tecnologia Assistiva (TA), Math Touch, que tem como intuito auxiliar pessoas com Deficiência Visual (DV) no desenvolvimento de conceitos básicos matemáticos (quatro operações), tendo continuidade na validação em uma Tese de Doutorado. A aplicação é composta por um sistema embarcado que serve como ferramenta de apoio para a aquisição e a compreensão dos conceitos envolvendo as operações básicas da Matemática. Sua primeira validação foi efetivada com um grupo de 11 professores que ensinam Matemática na qual foi possível constatar o potencial da TA. Posteriormente, a TA foi validada com a interação de um grupo de 5 estudantes do Ensino Fundamental, sendo que a análise permite inferir que a Math Touch se constitui em uma tecnologia auxiliar para a educação matemática.
\end{abstract}

Palavras-chave: Tecnologia Assistiva; Sistema Embarcado; Educação Matemática; Educação Inclusiva.

\begin{abstract}
This paper is a cut-off of the monograph of course completion in Computer Science, describing the implementation of Assistive Technology (TA), Math Touch, which aims to assist people with Visual Impairment (DV) in the development of basic mathematical concepts operations), and continued validation in a $\mathrm{PhD}$ thesis. The application is composed of an embedded system that serves as a support tool for the acquisition and understanding of concepts involving the basic operations of Mathematics. His first validation was carried out with a group of 11 teachers who teach mathematics in which it was possible to verify the potential of TA. The same one was validated later with a group of 5 students of Elementary School, where it was verified through the interaction an important aid in the education.
\end{abstract}

Keywords: Assistive Technology; Embedded System; Mathematics Education; Inclusive Education.

\section{Introdução}

Parte dos problemas envolvendo o ensino de Matemática pode se originar de uma experiência insatisfatória, no início do aprendizado de conceitos básicos. Para crianças

\footnotetext{
${ }^{1}$ Graduado em Ciência da Computação pela Universidade Luterana do Brasil (ULBRA), Gravataí, Rio Grande do Sul, Brasil. E-mail: julianomoeller@gmail.com

${ }^{2}$ Mestre em Ensino de Ciências e Matemática pela Universidade Luterana do Brasil (ULBRA). Docente da Universidade Luterana do Brasil (ULBRA), Guaíba, Rio Grande do Sul, Brasil. E-mail: masganzerla@gmail.com

${ }^{3}$ Doutor em Informática na Educação, Universidade Federal do Rio Grande do Sul (UFRGS). Docente do Pós-Graduação em Ensino de Ciências e Matemática - PPGECIM da Universidade Luterana do Brasil (ULBRA), Canoas, Rio Grande do Sul, Brasil. E-mail: marlisegeller@gmail.com
} 
com alguma limitação visual, um dos recursos utilizados como apoio é o uso da Tecnologia Assistiva, trazendo a possibilidade de adaptação de materiais.

A partir desse contexto e dos estudos realizados no LEI (Laboratório de Estudos de Inclusão), constitui-se o projeto "Tecnologias Assistivas para a Educação Matemática no Ensino Fundamental"4 , tendo entre suas ações a implementação da Math Touch, parte do Trabalho de Conclusão de Curso Ciências da Computação da Ulbra Gravataí/Brasil, norteado pela pergunta de pesquisa: "Quais as potencialidades e limitações da Math Touch para auxiliar no ensino de conceitos matemáticos básicos por meio da interação de alunos deficientes visuais?", com contribuições de uma Tese de Doutorado ${ }^{5}$ do Programa de Pós-Graduação em Ensino de Ciências e Matemática (PPGECIM) da ULBRA Canoas/Brasil, fazendo uso da Tecnologia Assistiva para adaptar os princípios do Material Dourado, afim de auxiliar no desenvolvimento de conceitos matemáticos básicos de crianças com deficiência visual, ingressantes no Ensino Fundamental, enfatizando o entendimento da contagem e operações matemáticas básicas.

\section{Deficiência Visual, Educação Matemática e Inclusão}

A visão é um dos sentidos que auxilia na compreensão do mundo de uma forma global e, ao mesmo tempo, permite estabelecer um significado para os objetos, conceitos e ideias ao ser humano. A comunicação por meio de imagens e elementos visuais pode ser definida como "comunicação visual" e as pessoas a empregam desde o raiar dos tempos. Com relação aos sentidos, Sá, Campos e Silva (2007, p. 14) afirmam que o sistema visual detecta e integra de forma instantânea e imediata cerca de $80 \%$ dos estímulos do ambiente que o indivíduo está inserido, ilustrando de forma clara e objetiva a dependência do ser humano perante a visão.

A deficiência visual pode ser definida como o comprometimento parcial, entre 40 e $60 \%$, ou total da visão, sendo de forma congênita ou adquirida. Segundo critérios estabelecidos pela Organização Mundial de Saúde (OMS, 2015) os graus de deficiência visual podem ser classificados em três grupos, sendo:

1. Baixa visão (leve, moderada ou profunda) - pode ser compensada com o uso de lentes, lupas, telescópios, com o auxílio de bengalas e treinamentos de orientação.

\footnotetext{
${ }^{4}$ Aprovado pelo Edital de Apoio a Projetos de Tecnologia Assistiva - CNPq/MCTIC/SECIS No 20/2016.

${ }^{5}$ Pesquisa aprovada pelo Comitê de Ética sob protocolo número CAAE: 66101616.5.0000.5349
} 
2. Próximo à cegueira - quando a pessoa ainda é capaz de distinguir luz e sombra, porém já faz uso do sistema braille ${ }^{6}$ para ler e escrever, utiliza recursos de voz para ter acesso a programas de computador, locomove-se com bengala e necessita de treinamentos de orientação e mobilidade.

3. Cegueira - quando não existe qualquer percepção de luz. Para estes casos, o sistema braile, a bengala e os treinamentos de orientação e mobilidade são fundamentais.

A falta de visão não interfere na capacidade intelectual e cognitiva de alunos com deficiência visual, pelo contrário, eles têm o mesmo potencial de aprendizagem e podem demostrar um desempenho escolar equivalente ou superior ao de alunos videntes mediante condições e recursos adequados. Podem apresentar lentidão na realização de algumas atividades, visto que a dimensão analítica da percepção tátil demanda mais tempo. Isso se origina da necessidade que eles têm de manipular e explorar o objeto para conhecer as suas características e fazer uma análise detalhada das partes para extrair suas próprias conclusões. Essa diferença básica e crucial é muito importante porque influi na elaboração de conceitos e interiorização do conhecimento.

Conforme Sá, Campos e Silva (2007, p. 15) "os sentidos têm as mesmas características e potencialidades para todas as pessoas. As informações tátil, auditiva, sinestésica e olfativa são mais desenvolvidas pelas pessoas cegas porque elas recorrem a estes sentidos com uma maior frequência para decodificar e guardar na memória as informações. Sem a visão, os demais sentidos passam a receber a informação de forma intermitente e fragmentada". Também cabe destacar que a

[...] audição desempenha um papel relevante na seleção e codificação dos sons que são significativos e úteis. A habilidade de atribuir significado a um som sem perceber a sua origem é difícil e complexa. A experiência tátil não se limita ao uso das mãos. O olfato e paladar funcionam conjuntamente e são coadjuvantes indispensáveis. [...]. As retas, as curvas, o volume, a rugosidade, a textura, a densidade, as oscilações térmicas e dolorosas, entre outras, são propriedades que geram sensações táteis e imagens mentais importantes para a comunicação, a estética, a formação de conceitos e de representações mentais (SÁ; CAMPOS; SILVA, 2007, p. 15).

As pessoas com deficiência, muitas vezes, passam por situações complexas e constrangimentos quando iniciam sua vida escolar, pois recebem e organizam a informação em um contexto impregnado de padrões de referências e experiências eminentemente visuais, que se caracteriza em uma clara desvantagem perante seus colegas.

\footnotetext{
${ }^{6}$ Sistema Braille: é um processo de escrita e leitura baseado em 64 símbolos em relevo, resultantes da combinação de até seis pontos dispostos em duas colunas de três pontos cada.
} 
Segundo Fernandes (2011), em um estudo realizado com alunos cegos, ficou claro que eles têm êxito nas representações de formas tridimensionais usando materiais que os permitam fazê-las tridimensionalmente. A autora ainda afirma que o conflito não gira em torno do "visto" ou do "sabido", e sim da natureza do material utilizado, de modo que o uso de material adequado favorece os aprendizes na representação do visto, ao contrário do que ocorre com os videntes. Em outro estudo realizado por Healy e Fernandes (2011) com cegos, fica evidenciado que

\begin{abstract}
para os sujeitos da pesquisa, o desenvolvimento dos conceitos em estudo ocorre a partir do domínio empírico que favorece a formulação de um arsenal de recursos multimodais, e segue em direção ao concreto e à experiência pessoal, ou seja, as conexões que eles estabelecem entre os conceitos matemáticos estudados e sua prática cotidiana (como dobrar o cobertor, o par de sapatos e as calças) só aconteceram quando os conceitos matemáticos assumiram algum significado ou quando foram parcialmente apropriados (HEALY; FERNANDES, 2011, p. 241).
\end{abstract}

Sendo assim, em um ambiente escolar frequentado por pessoas com deficiência, é fundamental explorar as potencialidades dos alunos. Portanto, as estratégias e as situações de aprendizagem para com eles devem valorizar a estimulação dos sentidos remanescentes, o comportamento exploratório, a iniciativa e a participação ativa.

Neste contexto aborda-se a importância do Material Dourado, que faz parte de um conjunto de materiais idealizados por Maria Montessori, médica e educadora italiana. Dentre os materiais idealizados por ela (SILVA; ARAUJO, 2011), o Material Dourado tem especial destaque, dado seu amplo uso ainda nos dias atuais e sua importância no aprendizado dos conceitos básicos da Matemática. É composto por cubos, placas, barras e cubinhos, apresentando sulcos em forma de quadrados, conforme mostra a Figura 1.

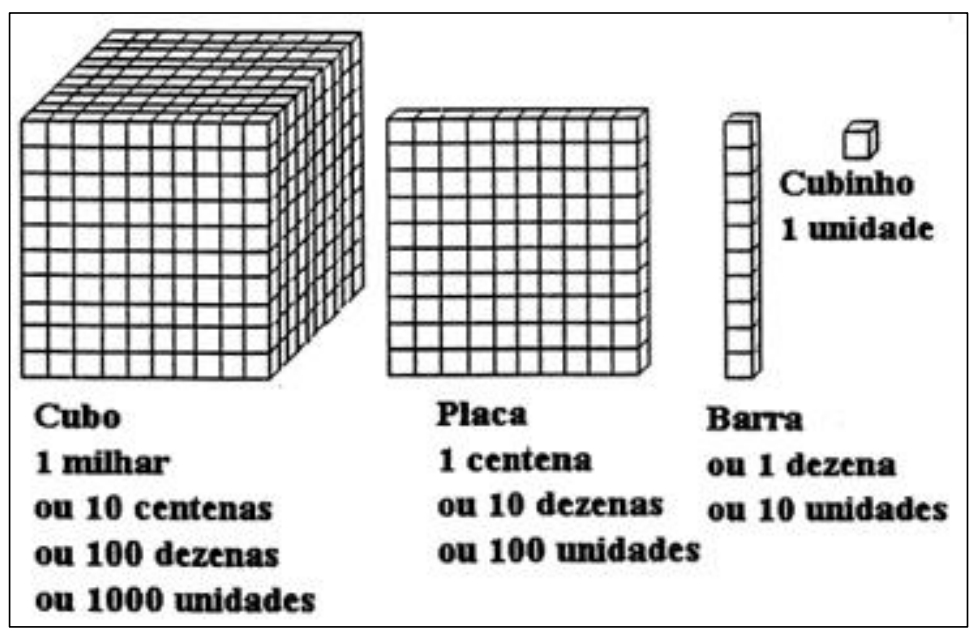

Figura 1: Representação atual do material dourado

Fonte: Silveira (1998) 
Observa-se que o cubo é formado por 10 placas, cada placa é formada por 10 barras, cada barra contém 10 cubinhos e o cubinho representa a unidade fundamental. Um dos principais objetivos deste material de apoio montessoriano é cooperar em atividades que auxiliam no ensino e na aprendizagem do sistema de numeração decimal-posicional e nos métodos utilizados para efetuar as operações fundamentais da Matemática.

O Material Dourado é de grande valia na educação e socialização das crianças na escola atual, pois, de acordo com Silveira (1998), seu uso auxilia a compreensão da técnica operatória do cálculo escrito, podendo assim calcular de diferentes maneiras, baseado nos princípios que regem o sistema posicional de numeração. A autora afirma ainda que também desperta na criança a concentração e o interesse, além de desenvolver sua inteligência e sua criatividade, pois é nesta faixa etária que ela possui uma maior predisposição aos jogos e desafios. Como resultado elas desenvolvem uma ideia mais objetiva de relações de graduação e proporção, o que as estimula a contar e a calcular de forma intuitiva e lúdica.

De acordo com Piaget (1978), as atividades lúdicas possuem um caráter educativo considerado crucial na formação psicomotora e na formação da personalidade das crianças. Ele afirma que os jogos são ferramentas indispensáveis para este processo, pois é através do contato e da interação com o outro que a criança vai internalizar conceitos básicos de convivência. Ainda segundo este autor (1977), a interação entre as crianças é indispensável para um desenvolvimento intelectual salutar, afirmando que:

[...] a lógica da criança não poderia se desenvolver sem interação social, porque é nas interações interpessoais que a criança se sente obrigada a ser coerente. Enquanto ela estiver sozinha, poderá dizer o que quiser pelo prazer do momento (PIAGET, 1977, p. 60).

Kamii (2012) infere que a construção mental é dada por etapas, sendo que a criança passa por um processo de formação e aquisição do conceito de número, formando assim o pensamento lógico-matemático,

ao coordenar as relações de igual, diferente e mais, a criança se torna apta a deduzir que há mais contas no mundo que contas vermelhas e que há mais animais do que vacas. Da mesma forma é coordenando a relação entre "dois" e "dois" que ela deduz que $2+2=4$ e que 2 x $2=4$ (KAMII, 2012, p. 19).

A autora ainda complementa que essa abstração do conceito do número é uma construção feita pela mente a partir das propriedades dos objetos conhecidos pelas crianças (KAMII, 2012). Ou seja, a habilidade de corresponder palavras (neste caso os números) a objetos. 
Para Piaget (1978), o pensamento lógico-matemático é uma construção resultante da ação mental da criança com relação ao mundo, gerado a partir de relações e laços desenvolvidos por ela durante sua atividade de pensar o mundo em conjunto com as ações realizadas sobre os objetos.

Pode-se inferir, portanto, que as pessoas com deficiência podem atingir as mesmas metas que seus pares videntes, em relação aos conceitos da Matemática, desde que se respeite a singularidade da forma que elas percebem o mundo. E um passo importante é encorajar professores, diretores, e educadores em geral a planejar ações que promovam a Educação Matemática Inclusiva.

Um grande aliado no âmbito da inclusão são as Tecnologias Assistivas presentes nas salas de aula regulares e salas de recursos. O conceito acerca do termo Tecnologia Assistiva, ou simplesmente TA, ainda é um tanto quanto novo e recente no contexto sociocultural atual, porém vem sendo constantemente revisado e debatido nos últimos anos, em função da sua importância e abrangência para garantir a inclusão de pessoas com deficiência. Sganzerla (2014) em sua pesquisa com professores, todos com experiência em ensino para deficientes visuais, constatou que muitos professores fazem uso de TA, porém desconhecem seu real significado. Ainda segundo a autora:

\begin{abstract}
Os professores que fazem parte das salas de recursos sabem seu conceito, uso, importância, muitos em função de cursos e oficinas oferecidas pela escola, município e estado e por utilizarem todos os dias com seus alunos. Porém, os professores de sala de aula regular fazem uso das TA, mas não sabem seu conceito (SGANZERLA, 2014, p. 78).
\end{abstract}

Segundo Galvão Filho (2009, p. 208) a expressão Assistive Technology teve sua origem no ano de 1988 na legislação norte-americana e estabelece critérios e bases legais que regulamentam a concessão de verbas públicas e subsídios para aquisição de materiais, contemplando recursos e serviços, que os cidadãos com deficiência necessitem. Com base nesse conceito, Bersch $(2008$, p.2) define TA como sendo "um arsenal de recursos e serviços que contribuem para proporcionar ou ampliar habilidades funcionais de pessoas com deficiência e consequentemente promover vida independente e inclusão".

Os recursos mencionados podem ser classificados como todo e qualquer item, equipamento, produto ou sistema que visam aumentar, manter ou melhorar as capacidades funcionais das pessoas com deficiência. Já os serviços são definidos como aqueles que visam auxiliar diretamente uma pessoa com deficiência a comprar, selecionar ou fazer uso dos recursos mencionados anteriormente.

Um exemplo de TA é a Contátil (Figura 2) que faz uso de um sistema embarcado para controlar a movimentação de três peças que representam grandezas matemáticas 
(centena, dezena e unidade), possibilitando assim a interação com o aluno cego através do tato e da audição. Conta com quatro modos de operação (SGANZERLA, 2014; SGANZERLA; GELLER, 2014; MARQUES, 2015):

- Aprendizado dos números, onde a partir de um valor inserido pelo teclado apresenta-o de forma tátil com a elevação das quantidades correspondentes, na Figura 2 é possível observar o valor 552;

- Calculadora, onde são inserindas duas parcelas e uma operação matemática e ao final apresenta o resultado de forma sonora e tátil;

- Calculadora tátil, inclui além da calculadora, a representação tátil das duas parcelas e do resultado;

- Atividades, sonoramente é apresentada uma operação matemática ou uma representação numérica e o usuário deve inserir via teclado a resposta e em seguida há a representação tátil.

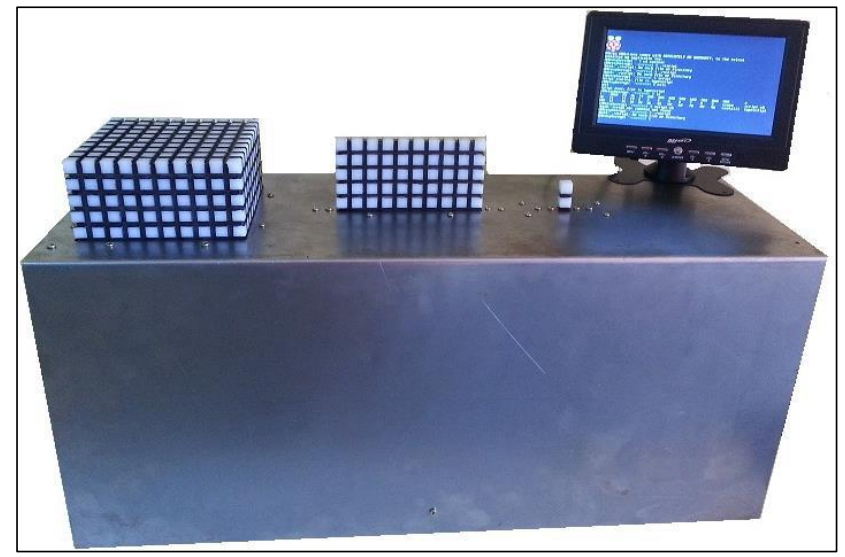

Figura 2: Representação do valor 552 pela Contátil Fonte: Sganzerla (2014, p. 96).

Diante de tantas possibilidades de recursos e formas de apoio, as tecnologias digitais apresentam-se como grandes aliadas na concretização do processo de inclusão, pois, segundo Sá, Campos e Silva (2007, p. 26) "recursos tecnológicos, equipamentos e jogos pedagógicos contribuem para que as situações de aprendizagem sejam mais agradáveis e motivadoras em um ambiente de cooperação e reconhecimento das diferenças".

\section{Trajetória Metodológica}

A Math Touch (MOELLER, 2016) foi idealizada a partir da validação da Contátil juntamente com estudos e pesquisas realizados no LEI em parceria com o Laboratório de 
Sistemas Digitais (LSD) ${ }^{7}$. A partir da inquietação de uma professora ${ }^{8}$ entrevistada, onde a mesma sugeriu que o aluno obtivesse maior participação na interação com a TA, surgiu o conceito de utilizar uma matriz de botões para que ele possa clica-los e assim estar inserindo a resposta aos questionamentos.

Foi definido como objetivo geral da pesquisa: implementar um protótipo da Tecnologia Assistiva Math Touch baseada na Contátil e no Material Dourado, para auxiliar no ensino de conceitos básicos de Matemática a alunos cegos e/ou baixa visão. Como objetivos específicos tem-se: desenvolver a TA Math Touch; validar considerando critérios de usabilidade, acessibilidade e robustez e avaliar potencialidades e limitações na perspectiva dos professores que atuam ou atuaram com alunos com deficiência visual.

Tendo como pergunta norteadora: "Quais as potencialidades e limitações da Math Touch para o ensino de conceitos matemáticos básicos por meio da interação de alunos deficiente visuais?”, buscou-se na implementação as ações para desenvolver, aplicar, validar e avaliar a TA, optando metodologicamente por duas vertentes: uma voltada para a implementação da TA, considerando o ciclo de desenvolvimento de software e hardware, e a outra, de cunho qualitativo descritivo, envolvendo a avaliação da TA na perspectiva de professores.

Na visão da Engenharia de Software, implementar está relacionado ao processo, desde a definição dos requisitos para o desenvolvimento até a sua validação, constituindo o ciclo de vida: Análise dos Requisitos; Projeto do Sistema e Programa; Codificação; Teste de Integração e Unidade, do sistema, de aceitação; Operação e Manutenção (PFLEEGER, 2004).

Após a implementação da Math Touch, optou-se por validar/avaliar, tendo como sujeitos professores que ensinam Matemática a alunos deficientes visuais. Para tanto foram elaboradas perguntas por meio de uma entrevista semiestruturada, por acreditar-se que dessa forma seria possível obter dados quanto a suas potencialidades. Marconi e Lakatos (2010, p. 180) relatam que "há liberdade total por parte do entrevistado, que poderá expressar suas opiniões e sentimentos". Os autores ainda afirmam que a função do pesquisador é de incentivo, levando o entrevistado a falar sobre o assunto de forma espontânea.

Por fim, a TA foi validada/experienciada por alunos deficientes visuais com a supervisão da professora do AEE (Atendimento Educacional Especializado) e a

\footnotetext{
${ }^{7}$ LSD - Laboratório de Sistemas Digitais do Curso de Ciência da Computação da ULBRA.

${ }^{8}$ Professora cega de nascença, com formação em Pedagogia e alfabetizadora a mais de 10 anos.
} 
doutoranda, sendo que os mesmos interagiram por meio de atividades pertencentes a Math Touch e outras propostas pela professora.

\section{Construção e Implementação da Match Touch}

A Math Touch (MOELLER, 2016) contitui-se em um sistema computacional que informa uma operação matemática e monitora a posição de um conjunto de botões móveis (Figura 3). Este, organizado na forma de uma matriz de 5 x 5, está à disposição do usuário, para que possa acioná-los e, por meio do tato, representar o conceito dos conjuntos numéricos. Quando o sistema propõe uma operação matemática o usuário poderá representá-la acionando os botões que julgar correto para representar a mesma.

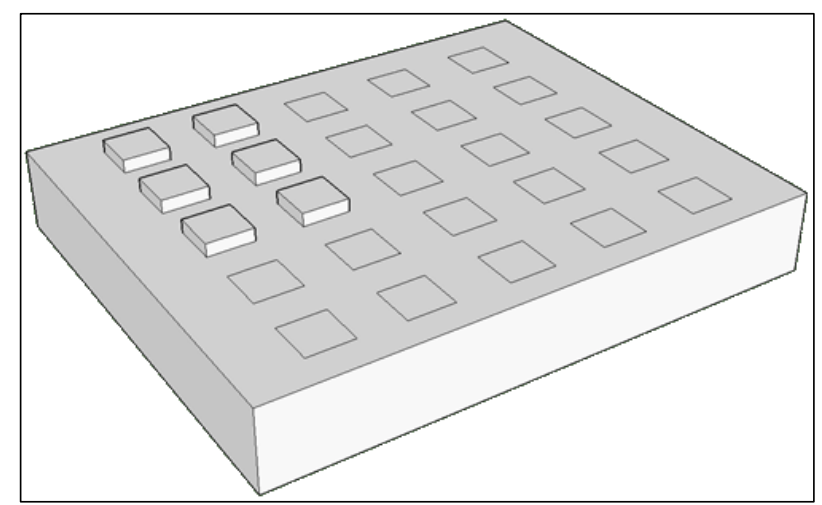

Figura 3: Protótipo inicial com a representação da operação de multiplicação $3 * 2$ Fonte: Moeller (2016, p. 46)

Conforme mostra a Figura 3, a matriz de botões propicia ao usuário simular inúmeras combinações de conjuntos numéricos, facilitando e aprimorando o conceito das operações matemáticas básicas. No exemplo em questão, formou-se três conjuntos com dois elementos em cada, ou ainda, dois conjuntos com três elementos cada, representando assim conceitualmente a operação de multiplicação matemática $3 * 2$ ou $2 * 3$.

O projeto utilizou como base o desenvolvimento de um sistema visando a interação com o usuário, conforme solicitação da professora entrevistada, tendo ele acesso a um menu de opções para selecionar um dos modos previstos: "Aplicando os conceitos matemáticos" ou "Desafio". Após a escolha do modo de operação, devem ser inseridos os dados relativos à operação matemática, que será informada de forma audível. Em seguida, o sistema aguarda a interação do usuário, que deve representar o resultado da operação na matriz de botões táteis e finalizar sua resposta. Ao final a aplicação interage de forma audível com o usuário validando sua resposta e retornando um áudio informando se a mesma está de acordo ou se ainda pode ser melhor trabalhada. 
A ferramenta contempla o processamento das quatro operações básicas da Matemática, sendo elas a adição, a subtração, a multiplicação e a divisão. As operações utilizam duas parcelas com números inteiros e positivos, limitados à quantidade máxima de botões que podem ser representados na matriz de interação, que nesse caso é de 25 (matriz 5 x 5). Outro fator importante, no caso da divisão, é a validação do valor resultante, devendo este também ser um número inteiro, para facilitar sua representação por parte dos alunos e por contemplar os conteúdos estudados nos anos iniciais do Ensino Fundamental. Se, por ventura, uma operação não prevista for inserida, o sistema a processa e informa o usuário que a mesma não é uma entrada válida. A Figura 4 apresenta a interface principal do sistema.

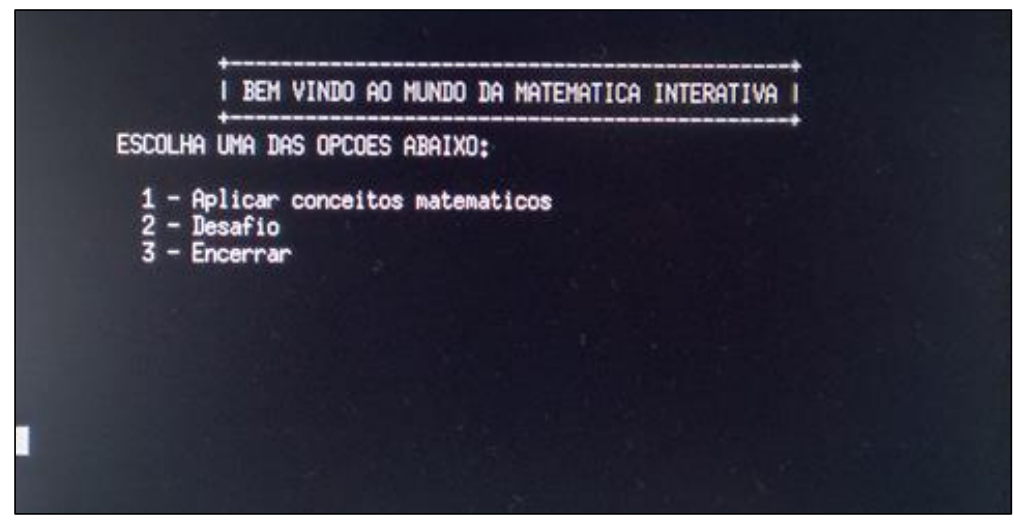

Figura 4: Tela inicial do sistema

Fonte: Moeller (2016, p. 47)

No modo de operação "Aplicando os conceitos matemáticos" (Figura 4) é solicitado ao usuário que insira uma operação matemática através do teclado. Após validá-la, o sistema solicita que represente seu resultado, através da matriz de botões tateáveis (Figura 5). A partir da leitura dos botões acionados (vermelhos), ocorre o processamento do valor representado e em seguida, a aplicação valida a resposta de forma audível, após o encerramento (botão verde).

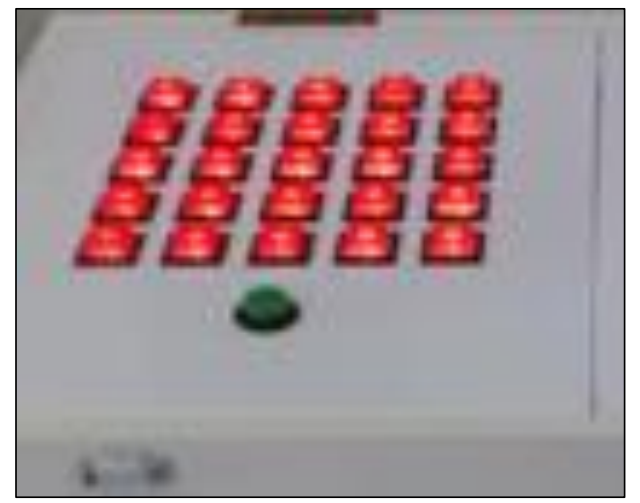

Figura 5: Matriz de botões tateáveis Fonte: A pesquisa 
Por fim, o modo de operação "Desafio" (Figura 4) propõe ao usuário uma forma lúdica de interagir com a Matemática. Sendo selecionada esta opção, a aplicação irá escolher as duas parcelas e a operação de forma aleatória, informando-a através do áudio correspondente. Para cada resposta correta serão somados pontos e ao final o usuário será informado da quantidade atingida em seu desafio.

O sistema pode ser operado de forma independente por um deficiente visual ou não, sendo necessária apenas a ajuda para inicializa-lo. A ferramenta informa através de áudios correspondentes o número e a opção correspondente para acessar cada modo de operação. Isso permite ao usuário opera-la sem auxílio externo, desde que tenha o domínio do uso do teclado numérico. Para melhor interação, está prevista a numeração em braile nas teclas do teclado numérico. O modo "Desafio" foi projetado para permitir completa independência do usuário com seus periféricos, visto que o sistema define de forma aleatória as parcelas com suas respectivas operações, sendo necessário apenas a interação com a matriz de botões tateáveis, conferindo ao equipamento uma independência e praticidade com relação a sua usabilidade.

É importante frisar que em todas as atividades propostas, apesar de treinarem e avaliarem os conhecimentos do indivíduo, o objetivo principal não passa por incentivar a competitividade, nem gerar frustração em caso de incertezas. Portanto, foram previstas mensagens positivas em caso de acertos, para que o usuário siga progredindo, e mensagens de apoio e incentivo para que se sinta motivado a tentar de novo, em caso de incorreções. Dessa forma, cria-se uma estratégia motivacional, onde o erro não seja destacado, mas o acerto seja reforçado e parabenizado.

Com relação à implementação, a Math Touch é constituída de um sistema embarcado utilizando os conceitos de TA para prover o máximo de praticidade e usabilidade aos usuários. Para tanto, foi projetado um gabinete que apresente tais características e que comporte todos os componentes de forma integrada e prática, tanto para seu uso quanto para sua mobilidade. A base de interação principal com o usuário é a matriz de botões tateáveis. Levando em conta o princípio do Material Dourado, esta matriz foi projetada para ter dimensões e características que se assemelham ao apresentado por ele. Para a implementação do projeto foram utilizadas as seguintes tecnologias: Mini-PC Raspberry Pi; Linux embarcado; Aplicação em linguagem C sendo executada no Raspberry Pi; Monitor para interface gráfica; Teclado numérico; Sistema de saída de áudio; Matriz de botões móveis tateáveis. 
Os botões utilizados na matriz tateável possuem características e dimensões ideais para o que se propõe. Eles apresentam um tamanho reduzido, similar ao tamanho das unidades utilizadas pelo Material Dourado e são resistentes quanto ao toque, característica importante para o manuseio por pessoas deficientes visuais, que irão explorá-los antes de acionar os mesmos. Para a iluminação foi necessária a construção de um circuito inversor, utilizando um transistor associado a leds de alto brilho e resistores, conforme mostra a Figura 6.

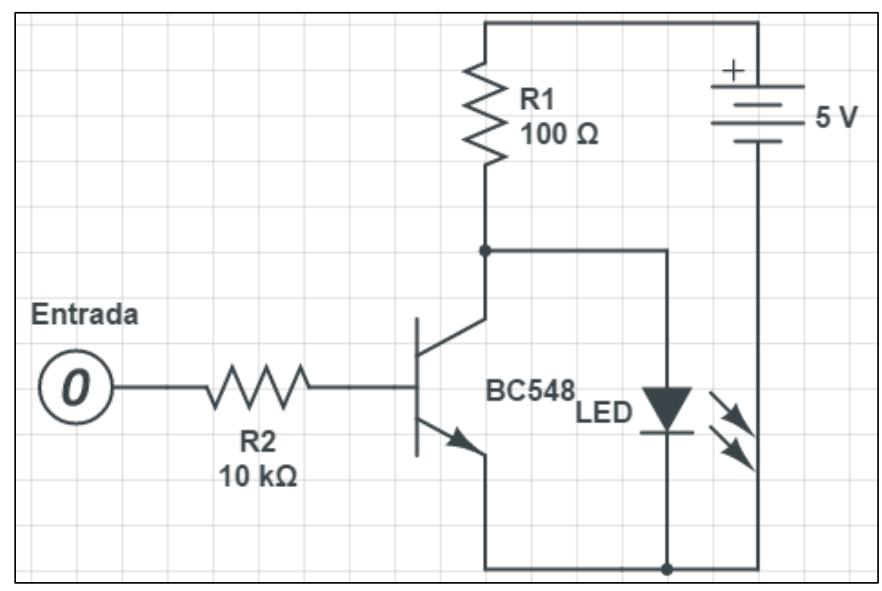

Figura 6: Circuito inversor usando transistor Fonte: Moeller (2016, p. 56).

A Raspberry Pi B+ dispõe de 28 pinos de GPIO configuráveis como entrada ou saída e a matriz de botões proposta totaliza 25 sinais para serem lidos pelo mini PC, ou seja, o mapeamento de sinais de entrada versus pinos disponíveis poderia ser um para um. Porém, desta forma não seria possível uma ampliação futura da matriz tateável, sendo necessário fazer alterações, tanto estruturais quanto de hardware e software para contemplar mais botões. Em função disso, foi elaborada uma leitura matricial dos botões, que exige apenas um pino de controle e um pino de leitura para cada linha da matriz, totalizando para o nosso caso 10 pinos de um total de 28 disponíveis na Raspberry (Figura 7). 


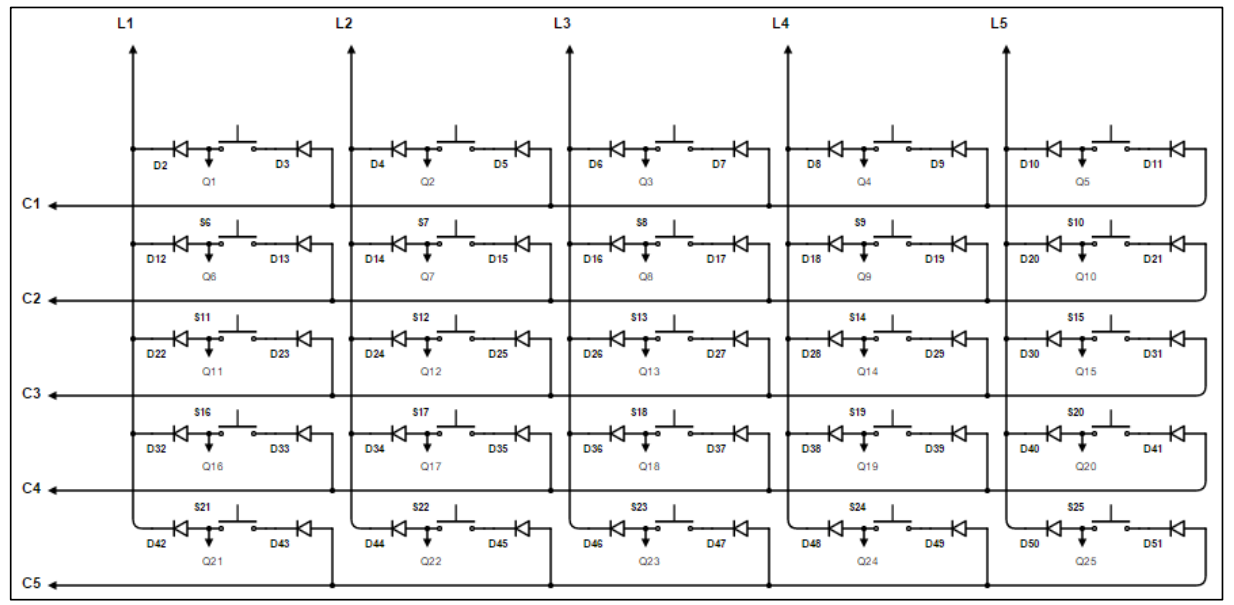

Figura 7: Circuito matricial para leitura dos botões

Fonte: Moeller (2016, p. 57)

Este circuito é capaz de, a partir dos 5 pinos de controle ( $\mathrm{C} 1$ a $\mathrm{C} 5)$ provenientes de sinais enviados pela Raspberry $\mathrm{Pi}$, interpretar os valores lógicos de cada botão, e lêlos através dos 5 pinos de leitura (L1 a L5) que são conectados a entradas da Raspberry. Foram utilizados diodos de resposta rápida do tipo 1N4148 para evitar que sinais de um botão interfiram em outro, forçando apenas um sentido para a corrente elétrica circular. Os sinais são lidos linha por linha, enquanto uma linha é habilitada pelo seu respectivo sinal de controle as outras linhas estão desabilitadas, garantindo uma leitura eficaz e configurável para a matriz de botões tateáveis. A Figura 7 mostra ainda, entre cada botão e o diodo, o ponto de ligação que irá servir de alimentação para a base de cada transistor dos circuitos inversores mostrados anteriormente (Q1 a Q25).

Como o objetivo da ferramenta é auxiliar crianças nos conceitos relacionados às operações básicas da Matemática, um dos requisitos é o aprendizado e o desenvolvimento do conceito dos conjuntos dos números. Em função disso foi elaborado um algoritmo de validação da resposta inserida na matriz de botões, sendo necessário que o aluno represente sua resposta de forma coerente. Como não se pode definir a lógica utilizada por cada criança para representar seus conceitos matemáticos, são contemplados agrupamentos feitos em linhas ou em colunas. Quando o resultado está correto, porém não agrupado em conjuntos, o sistema retorna um áudio orientando o usuário que sua resposta pode ser melhor representada. Neste momento a ação do educador se torna importante no aprendizado, podendo sugerir questões relacionadas ao conjunto dos números e propor uma discussão ao grupo de quais as possibilidades seriam pertinentes para o momento. A Figura 8 apresenta a versão final do projeto. 


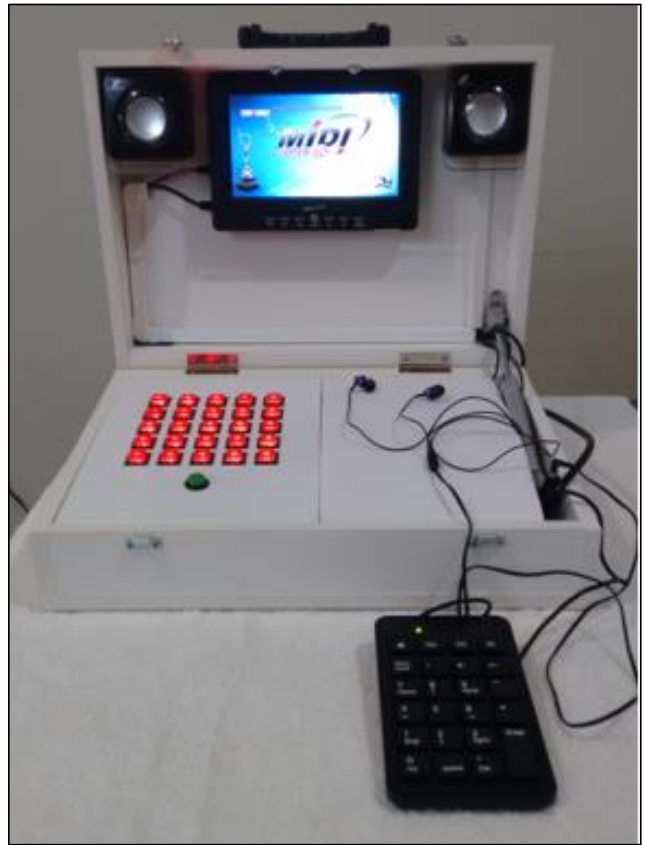

Figura 8: Projeto final da Math Touch Fonte: Moeller (2016, p. 65)

\section{Validação da Math Touch}

Para a validação da TA, professores foram entrevistados e manipularam a mesma, analisando e validando pontos como design, funcionalidade, robustez e desempenho como recurso didático matemático.

Os primeiros testes foram realizados por professores de diferentes áreas do conhecimento, sendo a grande maioria com formação em Matemática e alguns com experiência em educação especial. De um total de 11 avaliadores, 6 atuam na área da Matemática e 5 ensinam Matemática no Ensino Fundamental. Destaca-se ainda que 5 professores entrevistados possuem larga experiência com ensino de Matemática para alunos cegos e/ou com baixa visão, o que agrega valor no aspecto da validação.

As entrevistas foram registradas e avaliadas para que, a partir das conclusões, sugestões e críticas apontadas, fosse possível aperfeiçoar questões relativas à estrutura, conceitos e funcionalidades do protótipo, tornando-o uma TA mais adequada e eficiente para o que se propõe.

Os professores aprovaram o Design proposto pela Math Touch, comentando que a cor branca do gabinete é ótima, porém os botões na cor vermelha contendo a borda preta não apresentam o contraste ideal para os alunos com baixa visão, sugerindo assim que sejam usados botões com a cor branca na iluminação das teclas, o que daria o contraste 
ideal com sua borda preta, melhorando sensivelmente seu uso por crianças com baixa visão. Um dos entrevistados relatou:

Os botões estão em uma disposição que facilita a interação dos alunos, próximos e alinhados, porém a cor vermelha não é a mais adequada, pois ofusca a visão restrita dos alunos com baixa visão, mas o fato do gabinete ser da cor branca facilita e salienta a matriz.

Outra fala importante sobre o design foi proferida por um professor que atua com cegos nos anos iniciais

Todas as tecnologias/placas estão "escondidas", isso é um ponto importante, pois o aluno cego enxerga com os dedos e a primeira interação deles com o equipamento será de tatear na busca do reconhecimento/reconhecimento.

Quanto a robustez, foi constatado que o protótipo se comportou sem problemas e com perfeito funcionamento ao que foi proposto durante a execução dos testes. Mencionaram que a placa do mini PC permite que sejam acoplados outros equipamentos como uma televisão e um projetor, sendo este um ponto positivo. Como sugestão de melhoria foi proposto resetar a posição dos botões móveis automaticamente para que o aluno tenha mais autonomia ao trabalhar com a ferramenta de apoio ao ensino, visto que hoje essa inicialização é feita manualmente. Também sugeriram a expansão da matriz de botões para 10x10, permitindo assim trabalhar com a casa das centenas.

É importante que a TA possa ser adaptada à realidade de cada situação, a possibilidade de acoplar fone de ouvido, uma TV ou mesmo um projetor é de grande valia para os alunos com baixa visão.

Os professores entrevistados foram unânimes em considerar que a Math Touch se caracteriza como sendo uma TA com potencial para o ensino da Matemática. Mencionaram que o áudio é de qualidade, legível, com entonação e volume ideal. Apontaram ainda a qualidade do teclado numérico utilizado, sugerindo que fossem usados os números em braile, para facilitar o acesso e a utilização da ferramenta por parte dos alunos que estão em fase de reconhecimento da representação numérica.

O teclado utilizado está na mesma disposição do teclado de mesa, isso facilita a memorização por parte dos alunos. Seria interessante nesse processo de reconhecimento numérico disponibilizar os números em braille, dessa forma o aluno teria mais momentos de contato com o braille.

A validação com alunos em fase de alfabetização matemática está sendo realizada como parte da Tese de Doutorado da orientadora da monografia, que busca refletir sobre o uso de TA com alunos deficientes visuais, sendo que alguns relatos já foram finalizados (SGANZERLA; GELLER, 2018). 
O grupo de validação é composto por 5 alunos, todos do Ensino Fundamental, identificados por Aluno1, Aluno2, e assim sucessivamente, tendo como características:

- Aluno1: cursando o $1^{\circ}$ ano, baixa visão, em fase de alfabetização numérica, com muitas dificuldades na contagem e conservação do número;

- Aluno2: cursando o $3^{\circ}$ ano, cego (existe um resquício de visão em torno de 5\% no olho direito), possui domínio numérico até as centenas, entende a adição e subtração, bem como a multiplicação;

- Aluno3: cursando o $4^{\circ}$ ano, cego (com resquício de visão em torno de $5 \%$ em ambos os olhos), possui compreendimento das quatro operações básicas conhecendo valores até a casa do milhar;

- Aluno4: cursando o $5^{\circ}$ ano, baixa visão, com domínio numérico até a casa dos milhões;

- Aluno5: cursando o $9^{\circ}$ ano, cego de nascença, possui o domínio numérico das dezenas, com muita dificuldade efetua operações de soma e subtração, sendo considerado em fase de alfabetização numérica.

A metodologia utilizada para validar foi proposta pela professora do AEE (Atendimento Educacional Especializado), sendo composta pelas seguintes fases:

- Exploração da TA, onde os alunos a manusearam com o intuito de reconhecimento e esclarecimento de seu funcionamento (botões, sons, design), sendo que nessa etapa não houve nenhuma atividade ou desafio matemático;

- Representação dos números através da matriz de botões, onde a professora falava um valor e o aluno deveria clicar nos botões correspondentes, ou seja, na quantidade relativa ao valor;

- Aplicação dos conceitos matemáticos, nessa etapa a professora inseriu algumas operações matemáticas, iniciando com a soma, depois subtração, multiplicação e por fim divisão, e eles deveriam realizar os cálculos mentais ou com auxílio dos botões e representar o resultado dentro da matriz;

- Praticando os desafios, a partir das operações matemáticas ou valores informados pela Math Touch, os alunos deveriam representar seu resultado na matriz de botões.

\section{Discutindo os Resultados}

Validada pelo grupo de professores e apontada como sendo uma TA com potencial para auxiliar no ensino da Matemática básica, realizou-se a interação com os alunos e 
coleta dos dados, os quais serão relatados alguns dos momentos vivenciados. Durante a exploração da TA, observou-se que ao manusearem o equipamento surgiu a curiosidade de como era seu funcionamento, como seria utilizada, qual o seu propósito (Figura 9).

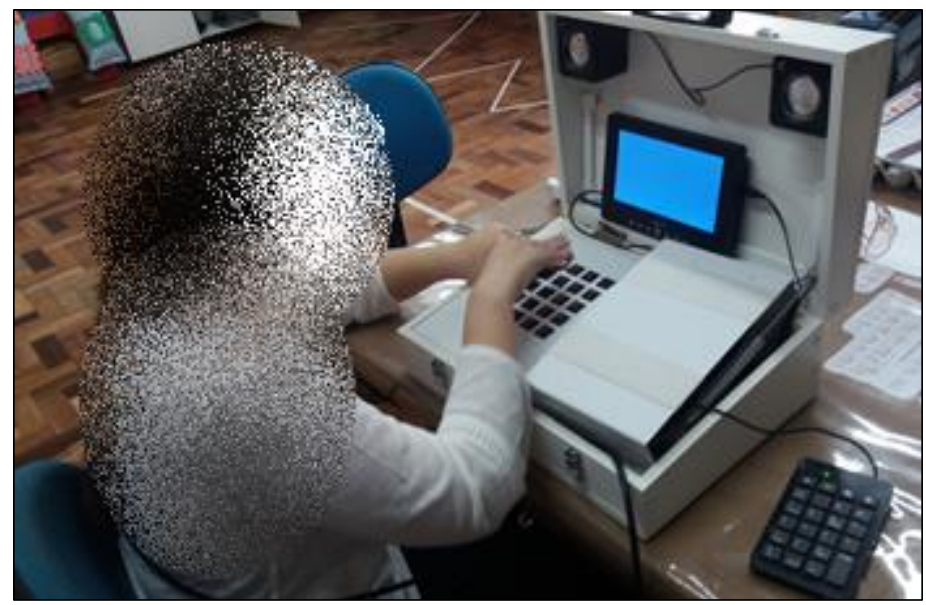

Figura 9: Interação do Aluno5 com a Math Fonte: A pesquisa

A importância da exploração da TA se deve ao fato de que os cegos desenvolvem imagens mentais, conceitos de objetos e quantidades a partir de suas experiências com o mundo tátil e com a forma de linguagem que usam (FERNANDES et al., 2006). A contagem dos botões, a verificação das formas, dos equipamentos acoplados (teclado, monitor, caixas de som) constituem um mapeamento mental e dessa forma, quando solicitados a interagirem com as atividades, já estarão familiarizados.

TA mapeada mentalmente, hora de quantificar. A atividade constitui em a professora proferir um valor numérico para o aluno e este representa-lo na matriz de botões. Salienta-se que essa atividade não está disponível na TA, a mesma foi elaborada pela professora do AEE, observando que poderia usufruir do equipamento de uma forma nova. $\mathrm{O}$ fato de os botões mudarem de posicionamento ao serem clicados, trouxe uma grande vantagem para os alunos cegos e/ou baixa visão, pois com o tato ficava evidenciada a quantidade já pressionada. 


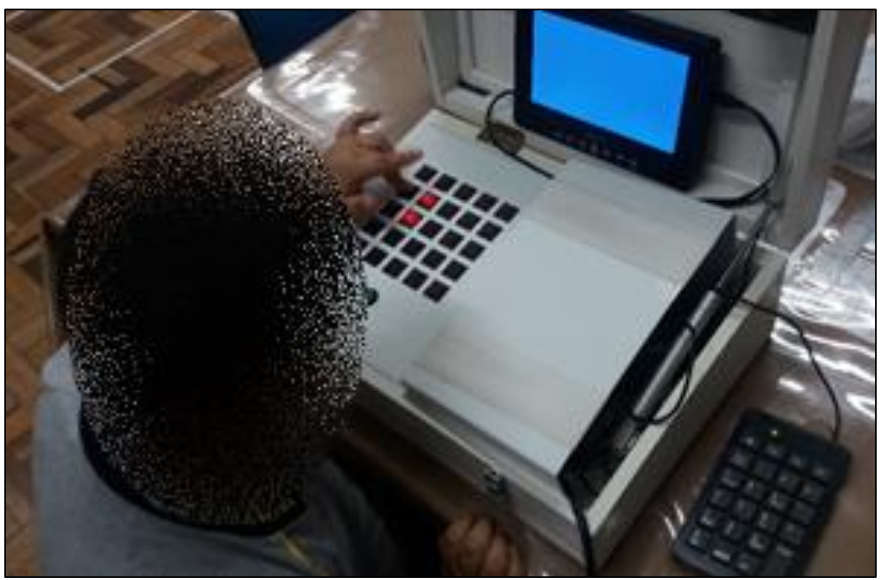

Figura 10: Interação do Aluno1 com a Math Fonte: A pesquisa

Observamos na Figura 10 o Aluno1 representando o valor 5, solicitado pela professora. A cada botão pressionado, o mesmo recitava os valores (um, dois, três, quatro, cinco), sendo esta prática percebida no exercício da habilidade de corresponder palavras (nesse caso os números) a objetos (botões). Kamii (2012) relata que a abstração do conceito do número é uma construção feita pela mente a partir das propriedades dos objetos conhecidos pelas crianças.

A professora, ao acompanhar a interação do Aluno1, afirmou: "Dessa forma é possivel observar e acompanhar a contagem do aluno, pois ele possui algumas dificuldades na ordem instável do número, muitas vezes ele recita um valor que não corresponde ao real'. Os autores Gelman e Gallistel (1978), retomados por Nunes e Bryant (1997), afirmam que a ordem estável consiste em recitar os números em uma ordem constante ao contar, não se pode contar 1, 2, 3 em um momento e em outro 1, 3, 2.

Outro fato observado como positivo para essa atividade, é a questão dos botões serem estáticos, não se moverem com o manuseio, o que muitas vezes acontece com a mesma atividade utilizando o Material Dourado, pelas unidades serem cubinhos soltos.

$\mathrm{Na}$ aplicação dos conceitos matemáticos, as atividades propostas foram as quatro operações básicas, iniciando pela adição e seguindo com substração, multiplicação e divisão. O objetivo foi de verificar como procediam as operações mentais.

Esse processo de abstração mental "acompanhada de tomada de consciência e de uma formulação - na verdade de uma formalização - dos elementos que foram abstraídos" é apresentado pelos autores Montangero e Maurice-Naville (1998, p.41) em seus estudos sobre abstração reflexiva piagetiana. Ainda argumentam que o raciocínio é fundamental nas atividades matemáticas. 


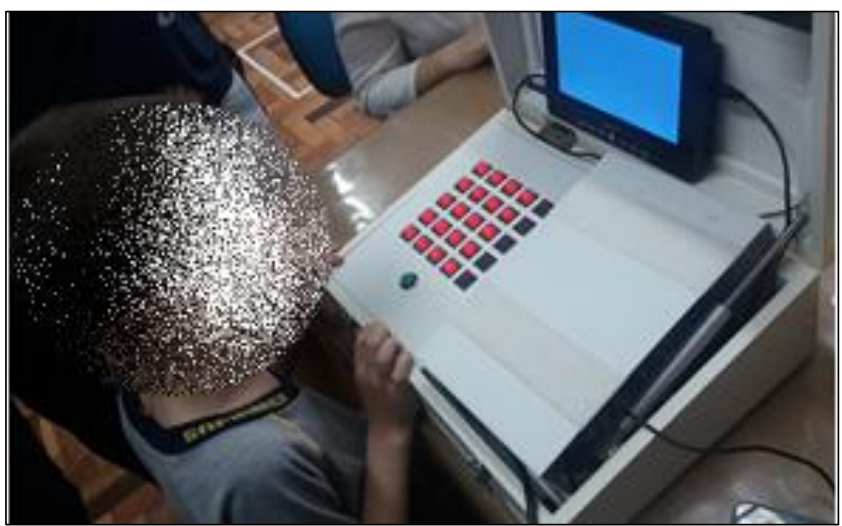

Figura 11: Interação do Aluno3 com a Math Fonte: A pesquisa

O Aluno3 (Figura 11), por já ter compreendido as operações matemáticas básicas e fazer uso do raciocínio lógico, apresentou um desempenho satisfatório em praticamente todas as atividades. Ao ser proporcionado um cálculo automaticamente ele recitava em voz alta o resultado e interagia com a Math, esperando que a mesma devolvesse uma mensagem de parabéns.

É importante frisar que a TA proposta neste artigo não visa em momento algum substituir o educador em sala de aula, e sim ser uma ferramenta de apoio a ele para que, em momentos oportunos possa propor uma discussão junto ao grupo, ou ainda uma melhor solução ao problema proposto, apontando assim outros caminhos para a obtenção da resposta. Por isso a Math Touch possibilita que, em casos de insucesso o aluno possa refletir sobre suas conclusões e remodelar, tanto mentalmente quanto de forma representativa, uma nova resposta sempre com o auxílio do educador. Esse modelo de elaboração do pensamento lógico-matemático faz despertar na criança uma ação versus reflexão, que se mostra efetiva ao auxiliar no conhecimento sobre diferentes estágios de inserção. Assim as particularidades do indivíduo são respeitadas e todos caminham na mesma direção rumo ao aprendizado.

O fato do feedback ser apresentado automaticamente trouxe uma empolgação ao aluno, mesmo quando ele não acertou uma das operações, pois a TA proporcionou uma nova chance de revisar o cálculo e apresentar novamente, o que para a professora se mostrou muito importante: "apontar o erro e proporcionar um aprendizado é muito importante nessa etapa da alfabetização matemática, pois é possível verificar o que não está de acordo e construir uma nova resposta". Ainda salienta que "O erro pode ser trabalhado com a interação de outro colega, ou até mesmo do professor, afim de buscar o cálculo ou representação correta". 
O Aluno4 realizou os desafios propostos com facilidade, visto que a matriz compreende os valores até 25 . Observamos que mesmo sendo atividades fáceis para o seu nível de conhecimento, foram realizadas com muita atenção e dedicação.

A experiência com esse grupo de crianças, interagindo, estudando, analisando e relatando suas vivências fez surgir uma gama de possibilidades de novas atividades e desafios e sobretudo um melhor entendimento sobre a deficiência visual e suas necesssidades.

\section{Considerações finais}

A partir do estudo desenvolvido, é possível compreender que a tecnologia tem se tornado um fator cada vez mais presente em nosso cotidiano, passando a integrar, gradual e naturalmente, cada vez mais o dia a dia das pessoas e os ambientes que estas frequentam e convivem. Essa tecnologia também atinge o ensino, trazendo qualidade e acessibilidade.

Com este propósito, as TA têm uma escala de importância relevante no processo de ensino dentro das escolas, visto que elas se propõem a minimizar a curva de aprendizado de alunos com deficiências. Foi com este objetivo que desenvolvemos a Math Touch, como uma ferramenta que auxilia no aprendizado de conceitos matemáticos referentes às operações básicas e dos conjuntos dos números, podendo ser utilizada tanto por alunos com deficiência visual como por videntes, tanto em sala de aula regular quanto em sala de recursos.

Dessa forma, fica evidenciada a potencialidade e o valor educacional ao que se propôs no projeto da Math Touch, auxiliar na aquisição de conhecimentos básicos matemáticos a crianças com deficiência visual e/ou baixa visão, com foco nas operações básicas, sendo elas a adição, subtração, multiplicação e divisão.

A interação dos alunos cegos e/ou baixa visão com a Tecnologia Assistiva, apesar da sua restrição física, apresentaram um entendimento da representação numérica e manuseio tátil satisfatórios, sendo que a observação por parte dos pesquisadores e professores, enquanto executavam suas ações para a resolução das atividades propostas, fez surgir a possibilidade de novas atividades e desafios.

Ressaltamos que a tecnologia desenvolvida está sendo reestruturada com base em melhorias e novas funcionalidades, a partir do Edital de Apoio a Tecnologia Assistiva. Tem-se por objetivo a implementação de novas funcionalidades como a matriz de botões com capacidade de centena (10x10), mudança das cores dos botões para branca/ 
transparente, inserção de atividades para contagem (sugestão da professora do AEE), bem como vídeos em Libras para que pessoas com deficiência auditiva também possam usufruir da mesma.

\section{Referências}

BERSCH, R. Introdução à Tecnologia Assistiva. Porto Alegre: CEDI - Centro Especializado em Desenvolvimento Infantil, 2008.Disponível em:

<http://200.145.183.230/TA/4ed/material_apoio/modulo2/M2S1A5_Introducao_TA_Rita_Bers ch.pdf>. Acesso em: 09 fev. 2017.

FERNANDES, C. T. et al. A construção do conceito de número e o pré-soroban. Brasília: Ministério da Educação, Secretaria de Educação Especial, 2006.

FERNANDES, S. H. A. A. Relações entre o "visto" e o "sabido": as representações de formas tridimensionais feitas por alunos cegos. Revista Iberoamericana de Educação Matemática, Venezuela, número 26, p. 137-151, jun. 2011. Disponível em:

<http://www.matematicainclusiva.net.br/pdf/Relacoes_entre_o_visto_e_o_sabido_as_representa coes_de_formas_tridimensionais_feitas_por_alunos_cegos.pdf $>$. Acesso em: 29 mar. 2015.

GALVÃo FILHO, T. A. A Tecnologia Assistiva: de que se trata? 1. ed. Porto Alegre: Redes Editora, 2009. p. 207-235.

GELMAN, R.; GALLISTEL, C.R. The child's understanding of number. 1. ed. Cambridge: Harvard University Press, 1978.

HEALY, L; FERNANDES, S. H. A. A. Relações entre atividades sensoriais e artefatos culturais na apropriação de práticas matemáticas de um aprendiz cego. Educar em Revista [online], Curitiba, v. 27, n. Especial, p. 227-243, 2011. Disponível em:

$<$ http://www.matematicainclusiva.net.br/pdf/Relacoes_entre_atividades_sensoriais_e_artefatos_ culturais_na_apropriacao_de_praticas_matematicas.pdf>. Acesso em: 04 abr. 2018.

KAMII, C. A criança e o número: implicações educacionais da teoria de Piaget para a atuação com escolares de 4 a 6 anos. 39. ed. Campinas: Papirus, 2012.

MARCONI, M. de A.; LAKATOS, E. M. Fundamentos da metodologia científica. 7. ed. São Paulo: Atlas, 2010.

MARQUES, C. M. Contátil: A matemática na ponta dos dedos. 2015. 67 f. Trabalho de conclusão de curso (Graduação em Ciência da Computação) - Instituto de Computação, Universidade Luterana do Brasil, Gravataí, 2015.

MOELLER, J. D. Math Touch - Uma Alternativa à Visão. 2016. $74 \mathrm{f}$. Trabalho de conclusão de curso (Graduação em Ciência da Computação) - Instituto de Computação, Universidade Luterana do Brasil, Gravataí, 2016.

MONTANGERO, J.; MAURICE-NAVILLE, D. Piaget ou inteligência em evolução. 1. ed. Porto Alegre: ArtMed, 1998.

NUNES, T; BRYANT, P. Crianças Fazendo Matemática. 1. ed. Porto Alegre: Artmed, 1997.

OMS. Organização Mundial de Saúde. Dados de Saúde, Brasília, 2015. Disponível em: <http://www.paho.org/bra/>. Acesso em: 15 de mar. 2017. 
PFLEEGER, S. L. Engenharia de software: teoria e prática. 2. ed. São Paulo: Prentice Hall, 2004.

PIAGET, J. Psicologia da inteligência. Tradução de Egléa de Alencar. 2. ed. Rio de Janeiro, Zahar, 1977.

PIAGET, J. A formação do símbolo na criança. 4ª Edição. Rio de Janeiro, Zahar, 1978.

SÁ, E. D. de.; CAMPOS, I. M.; SILVA, M. B. C. Atendimento Educacional Especializado Deficiência Visual. Brasília: Ministério da Educação, 2007. Disponível em:

<http://portal.mec.gov.br/seesp/arquivos/pdf/aee_dv.pdf>. Acesso em: 12 mai. 2017.

SGANZERLA, M. A. R. Contátil: potencialidades de uma Tecnologia Assistiva para o ensino de conceitos básicos de matemática. 2014. 119 f. Dissertação (Mestrado em Ensino de Ciências e Matemática) - PPGECIM - Programa de Pós-Graduação em Ensino de Ciências e Matemática. Universidade Luterana do Brasil, Canoas, 2014.

SGANZERLA, M. A. R.; GELLER, M. Contátil: (Re)Adaptação do Material Dourado para Deficientes Visuais. RENOTE. Revista Novas Tecnologias na Educação, Porto Alegre, v. 12, n. 02, p. 1009-1019, dezembro. 2014.

SGANZERLA, M. A. R; GELLER, M. Tecnologias Assistivas e Educação Matemática: um estudo envolvendo alunos com deficiência visual no AEE. Acta Scientiae, Canoas, v. 20. n. 1. p. 36-55, jan./fev. 2018.

SILVA, S. A. da; ARAUJO, J. A. A. de. Maria Montessori e a Criação do Material Dourado como Instrumento Metodológico para o Ensino de Matemática nos anos iniciais da escolarização. Universidade Estadual de Mato Grosso do Sul (UEMS). Campo Grande, 2011. Disponível em: < https://docplayer.com.br/19241097-Maria-montessori-e-a-criacao-domaterial-dourado-como-intrumento-metodologico-para-o-ensino-de-matematica-nos-anosiniciais-da-escolarizacao.html>. Acesso em: $20 \mathrm{dez} .2018$.

SILVEIRA, J. A. da. Material Dourado de Montessori: Trabalhando com os algoritmos da Adição, Subtração, Multiplicação e Divisão. Ensino em Re-Vista, Uberlândia, v. 6, n. 1, p. 47 63, jul. 97/jun. 1998.

Recebido em: 10 de setembro de 2018 .

Aceito em: 14 de dezembro de 2018. 